\title{
Fatal infantile lactic acidosis with methylmalonic aciduria
}

INSERM

\section{Source}

INSERM. (1999). Orphanet: an online rare disease and orphan drug data base. Fatal infantile lactic acidosis with methylmalonic aciduria. ORPHA:17

Fatal infantile lactic acidosis with methylmalonic aciduria is a rare neurometabolic disease characterized by infantile onset of severe encephalomyopathy, lactic acidosis and elevated methylmalonic acid urinary excretion. Clinically it manifests with severe psychomotor delay, hypotonia, failure to thrive, feeding difficulties and dystonia. Epilepsy and multiple congenital anomalies may be associated. 